\title{
Fuzzy Comprehensive Evaluation Method in the Application of Evaluating Coaches' Competitive Performance Standards
}

\author{
Ye Yuan \\ Department of Computer Science,North China Electric Power University, Baoding 071000, China \\ hong198520@163.com
}

Keywords: fuzzy comprehensive evaluation,membership function.

Abstract. We apply the fuzzy comprehensive evaluation method into evaluating college coaches' competitive performance standards. Then focusing on men's hockey, we give the top 5 college hockey coaches through the model.

\section{Introduction}

In this question, our task is to build a mathematical model to choose the best coaches. The first thing we consider is the criterion of good college coach. By exploring a series of articles about evaluating coaches, we find that the public mainly focus on wins and losses of coaches when ranking coaches.

Aiming at competitive performance standards about college coach, we propose three concrete indexes, which involve average competitiveness, stability of competitiveness, competitive events. We make the following structure chart to illustrate our model.

Introduction of competitive performance standards:

Average competitiveness. We think the weighted value of the mean value of the winning ratio, failing ratio, tie ratio normal distribution can indicate the average competitiveness in a degree.

Stability of competitiveness. We think the weighted value of the standard deviation of the winning ratio, failing ratio, tie ratio normal distribution can indicate the stability of competitiveness in a degree.

Competitive events Competitive events mainly involve the number of RS (Conference Regular Season Champion), CT (Conference Postseason Tournament Champion), NCAAs (NCAA Tournament participant (finish)).

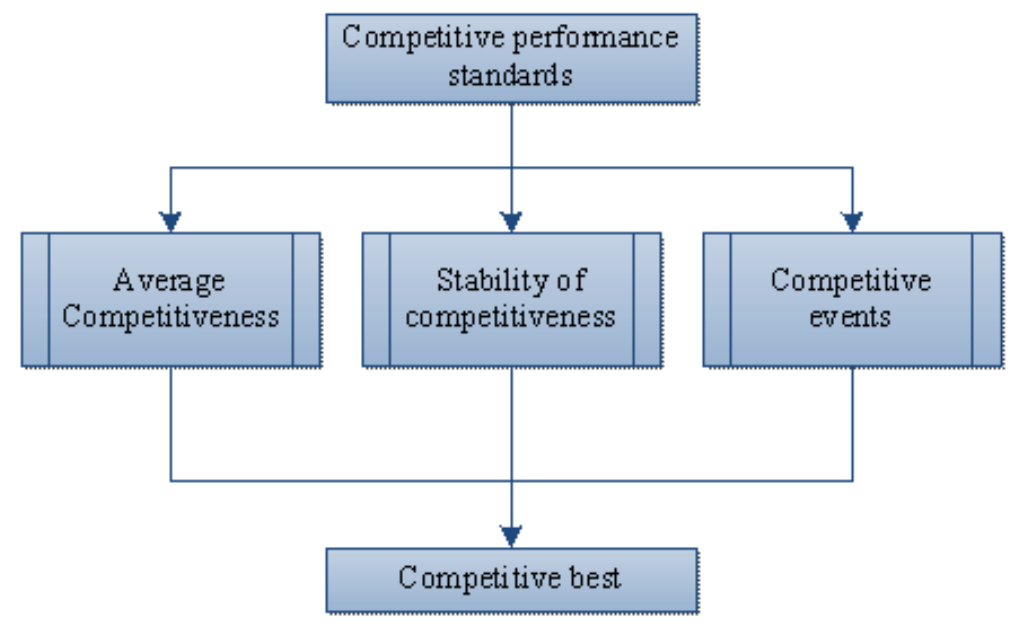

Figure 1: The ow chart

\section{Assumption}

Considering some factors that may make our model designing unable to carry out, we give some proper assumptions to simplify the problem as follow.

Evaluating coaches can’t cross between different genders and different sports. Because sports is classified by male and female, which indicate different genders may influence sports results, we think 
evaluating coaches should be classified bymale and female sports. In addition, different sports has different evaluation criterions, so we think evaluating coaches should be classified by sports

Evaluating coaches doesn't consider the period that one coach belongs to. Because evaluating one coach should consider his/her whole tenure, there are few coaches' tenure in the same period.

One coach's competitive performance has a positive correlation with the number of champions that the team one coach guides.

\section{Modeling}

After collecting data from the Internet, we can find vast quantities of coaches' information about various sports. On the base of first assumption, for illustrating our model, we just take college male hockey coach as example. Then, on the base of second assumption, we have collected data about nine hundreds of college male hockey coaches from 1900 to now. For reducing our workload, firstly we roughly select top 15 coaches.

Table1TOP fifteen College Hockey Male Coaches

\begin{tabular}{cccc}
\hline Number & Name & Number & Name \\
\hline 1 & Jack Riley & 9 & Dick Umile \\
2 & Red Berenson & 10 & Dean Fuller \\
3 & John Rolli & 11 & Bob Peters \\
4 & Bill Beaney & 12 & Terry Meagher \\
5 & Rick Gotkin & 13 & Ron Mason \\
6 & Jack Parker & 14 & George Gwozdecky \\
7 & Len Ceglarski & 15 & Jerry York \\
8 & Jeff Sauer & & \\
\hline
\end{tabular}

The Class of the average competitiveness. Nextly, we need to determine the value of the average competitiveness according to the mean value of normal distribution.

As a result of the vagueness of the average competitiveness, we make five classes, including A B C D E,A means best, B means better, C means good, D means ordinary, E means bad.

We define the following membership function to determine the degree of membership of the mean value of winning ratio. Failing ratio, tie ratio are similar with winning ratio. Then we adopt the Fuzzy Comprehensive Evaluation to determine the value of the average competitiveness. We adopt the analytic hierarchy process to determine the weights of winning ratio, failing ratio, tie ratio.

The membership function as follows:

$$
\begin{aligned}
& A(x)=\left\{\begin{array}{ll}
0 & \min <x \leq b_{1} \\
k\left(x-b_{1}\right) & b_{1}<x \leq 0.9 \max +0.1 \min \\
1 & 0.9 \max +0.1 \min <x \leq \max
\end{array} \quad B(x)= \begin{cases}0 & x \leq b_{2} \\
k\left(x-b_{2}\right) & b_{2}<x<0.7 \max +0.3 \min \\
1 & x=0.7 \max +0.3 \min \\
-k\left(x-b_{2}^{\prime}\right) & 0.7 \max +0.3 \min <x \leq \max \end{cases} \right. \\
& C(x)=\left\{\begin{array}{ll}
k\left(x-b_{3}\right) & \min \leq x<0.5(\max +\min ) \\
1 & x=0.5(\max +\min ) \\
-k\left(x-b_{3}^{\prime}\right) & 0.5(\max +\min )<x \leq \max
\end{array} \quad D(x)= \begin{cases}k\left(x-b_{4}\right) & \min \leq x<0.3 \max +0.7 \min \\
1 & x=0.3 \max +0.7 \min \\
-k\left(x-b_{4}^{\prime}\right) & 0.3 \max +0.7 \min <x \leq b_{4}^{\prime} \\
0 & x>b_{4}^{\prime}\end{cases} \right.
\end{aligned}
$$




$$
E(x)=\left\{\begin{array} { l l } 
{ 1 } & { \operatorname { m i n } \leq x < 0 . 1 \mathrm { max } + 0 . 9 \operatorname { m i n } } \\
{ - k ( x - b _ { 5 } ^ { \prime } ) } & { 0 . 1 \operatorname { m a x } + 0 . 9 \operatorname { m i n } \leq x < b _ { 5 } ^ { \prime } } \\
{ 0 } & { b _ { 5 } ^ { \prime } \leq x < \operatorname { m a x } }
\end{array} \left\{\begin{array}{l}
k=\frac{5}{3 \max -3 \min } \\
b_{1}=0.3 \max +0.7 \max \\
b_{2}=0.1 \mathrm{max}+0.9 \mathrm{~min} \\
b_{2}^{\prime}=1.3 \mathrm{max}-0.3 \mathrm{~min} \\
b_{3}=1.1 \mathrm{~min}-0.1 \mathrm{max} \\
b_{3}^{\prime}=b_{3}+1.2(\max -\min ) \\
b_{4}=1.3 \min -0.3 \max \\
b_{4}^{\prime}=b_{4}+1.2(\max -\min ) \\
b_{5}^{\prime}=0.7 \mathrm{max}-0.3 \mathrm{~min}
\end{array}\right.\right.
$$

The Class of the stability of competitiveness. Similarly, we need to determine the value of the stability of competitiveness according to the standard deviation of normal distribution. The stability of competitiveness is also vague, we deal with the standard deviation of winning ratio, failing ratio, tie ratio similarly. Then we also adopt the Fuzzy Comprehensive Evaluation to determine the Class of the stability of competitiveness. The format of membership function of standard deviation is similar with the mean value, so we don't list them.

The Class of competitive events. On the base of third assumption, we rank hockey coaches by the number of RC champions, CT champions, NCAAs (finished) in descending order. Similarly, we also get the degree of membership of competitive events according to the ranking.

Results of the sub model competitive performance standards:We adopt the Fuzzy Comprehensive Evaluation to determine the coach's competitive performance, the weights adopts the above results of the analytic hierarchy process.

\begin{tabular}{|c|c|c|c|c|c|}
\hline \multicolumn{7}{|c|}{ The results of competitive performance } \\
\hline $\begin{array}{c}\text { Class } \\
\text { Number }\end{array}$ & $\mathrm{A}$ & $\mathrm{B}$ & $\mathrm{C}$ & $\mathrm{D}$ & $\mathrm{E}$ \\
\hline 1 & .4097 & .2848 & .4578 & .6546 & .6316 \\
\hline 2 & .9542 & .6538 & .8220 & .6186 & .3070 \\
\hline 3 & .8182 & .6005 & .3726 & .1799 & .0986 \\
\hline 4 & .5494 & .4328 & .3054 & .2868 & .3487 \\
\hline 5 & .4042 & .3137 & .4219 & .5087 & .6004 \\
\hline 6 & .6381 & .4821 & .6436 & .6693 & .4525 \\
\hline 7 & .4834 & .5360 & .5655 & .5417 & .3739 \\
\hline 8 & .4463 & .4135 & .4714 & .4978 & .4833 \\
\hline 9 & .4385 & .3537 & .4496 & .5147 & .5343 \\
\hline 10 & .8366 & .6428 & .7057 & .4946 & .3028 \\
\hline 11 & .8562 & .7225 & .6957 & .5537 & .2729 \\
\hline 12 & .7772 & .5731 & .6939 & .5037 & .3577 \\
\hline 13 & .9079 & .7303 & .7388 & .4978 & .2039 \\
\hline 14 & .3514 & .3902 & .5043 & .5700 & .5222 \\
\hline 15 & .8398 & .6029 & .6820 & .6240 & .3496 \\
\hline
\end{tabular}

\section{Conclusion}

From the chart, we can know serial number 2 Red Berenson's competitive performance is best, serial number 13Ron Mason's competitive performance is best, serial number 11Bob Peters's competitive performance is best, serial number 15Jerry York's competitive performance is best, serial number 10 Dean Fuller's competitive performance is best. 


\section{References}

[1] http://en.wikipedia.org/wiki/Analytic_hierarchy_process

[2] Rowe and Wright. (2001): Expert Opinions in Forecasting. Role of the Delphi Technique. In:

Armstrong (Ed.): Principles of Forecasting: A Handbook of Researchers and Practitioners, Boston: Kluwer Academic Publishers.

[3] Blaine Gorney, R. Gary Ness. (2000). Evaluation Dimensions for Full-Time Head Coaches at NCAA Division II Institutions. Journal of Personnel Evaluation in Education, 14 (1), 47-65.

[4] Si Shoukui, Sun xijing. (2014). Mathematical Modeling. National Defense Industry Press, Beijing.

[5] http://www.uscho.com/stats/coaches/mens-hockey/\#ixzz3PuOyxujq

[6] http://www.uscho.com/stats/coaches/womens-hockey/\#ixzz3PuRCKpCw

[7] http://www.battlingbishops.com/coaches.aspx?path=msoc\&rc=9 